\title{
Synthesis and characterization of magnetically recoverable 1-(copperferritesiloxypropyl)-3-methylimidazolium heteropolytungstate ionic liquid as a new nanocatalyst for the preparation of $1 \mathrm{H}$-pyrazolo[1,2-b]phthalazine-5,10-diones
}

\author{
Hamid Reza Saadati-Moshtaghin ${ }^{1}$ - Farrokhzad Mohammadi Zonoz ${ }^{1}$ (D)
}

Received: 20 June 2017/ Accepted: 18 September 2017/Published online: 25 September 2017

(c) The Author(s) 2017. This article is an open access publication

\begin{abstract}
A novel, efficient and magnetically recoverable nanomaterial consisting of heteropoly acid supported on ionic liquid-modified copper ferrite nanoparticle was prepared and performed as a heterogeneous catalyst in the fast and convenient synthesis of $1 \mathrm{H}$-pyrazolo[1,2-b]phthalazine-5,10-dione derivatives under mild and solvent-free conditions. The synthesized nanomaterial was characterized with FT-IR, XRD, FESEM, TEM, ICP and VSM. Furthermore, the obtained nanomaterial displayed striking reusability in the titled catalytic reaction. Compared with the various previously reported catalysts, the newly synthesized nanocatalyst is found to be most efficient with regard to operation simplicity, reaction time, yield and ease of catalyst separation.
\end{abstract}

Keywords Magnetic nanoparticles · Heteropoly acid ·

Nanocatalyst · Ionic liquid · 1H-pyrazolo[1,2-

b]phthalazine-5,10-dione

\section{Introduction}

In recent years, considerable attention has been devoted to multi-component reactions (MCRs) due to their widespread applications in organic, medicinal and green chemistry. MCRs

Electronic supplementary material The online version of this article (doi:10.1007/s40097-017-0241-6) contains supplementary material, which is available to authorized users.

Farrokhzad Mohammadi Zonoz

f.zonoz@hsu.ac.ir; fzmohamadi@yahoo.com

1 Department of Chemistry, School of Science, Hakim Sabzevari University, Sabzevar 96179-76487, Iran reduce the number of steps, reaction time, use of solvents and by-products [1]. Furthermore, their simplicity, efficiency and cost-effectivity make them more attractive and useful in drug design [2]. MCRs have now been well used as an excellent synthetic method for the preparation of heterocyclic compounds. Nitrogen-containing heterocyclic compound, especially heterocycles containing bridgehead hydrazine, has attracted (immense or considerable) attention because of their pharmaceutical and biological properties. For example, $1 \mathrm{H}-$ pyrazolo[1,2-b]phthalazine-5,10-diones were reported as the anti-inflammatory, analgesic, anti-hypoxic, anti-pyretic agents [3].

There are several methods and different catalysts reported in the literature for the synthesis of $1 \mathrm{H}$-pyrazolo[1,2-b]phthalazine-5,10-diones such as use of ultrasonic irradiation [4], supported caesium carbonate [5], $\mathrm{CuI}$ nanoparticles [6], AlKIT-6 [7], $\mathrm{NiCl}_{2} \cdot 6 \mathrm{H}_{2} \mathrm{O}$ [8], $\mathrm{InCl}_{3}$ [9]. SBA-supported sulfonic acid [10], $p$-toluenesulfonic acid [11] and basic ionic liquid [12]. Most of the aforementioned techniques suffer from drawbacks such as prolonged reaction time, poor yields, pollution caused by toxic catalysts and solvents, numerous tedious steps and use of expensive catalysts or reagents which lead to restricted use of these derivatives in practical applications. Therefore, research on 1H-pyrazolo[1,2-b]phthalazine-5,10diones and finding a novel catalyst would be highly desirable.

On the other hand, room temperature ionic liquids (RTIls) are suitable reaction media for synthesis [12], catalysis [13], separation and extraction [14] which have attracted much interest among chemists. However, cost and viscosity are two major obstacles for their widespread industrial applications. Therefore, immobilization of ionic liquids on the surface of solid supports could be a good methodology to overcome these problems.

The choice of an efficient support is one of the most crucial steps in catalyst systems because an efficient 
support could significantly improve the activity, selectivity and recycling of catalyst. Recent interest in some type of metal oxide nanoparticles as a catalyst support stems from their magnetic property. Among the various magnetic nanoparticles, magnetite $\left(\mathrm{Fe}_{3} \mathrm{O}_{4}\right)$ is the most widely used catalysts support. However, the acidic environment reduces the magnetization of $\mathrm{Fe}_{3} \mathrm{O}_{4}$ because its $\mathrm{Fe}^{2+}$ content is readily oxidized. So, $\mathrm{Fe}_{3} \mathrm{O}_{4}$ nanoparticles must be synthesized under $\mathrm{N}_{2}$ atmosphere to prevent the air oxidation of $\mathrm{Fe}^{2+}$. Therefore, copper ferrite $\left(\mathrm{CuFe}_{2} \mathrm{O}_{4}\right)$ as a typical ferromagnetic oxide with spinel structure has high thermal stability, moderate magnetization and considerable chemical stability and could be excellent support for homogeneous catalysts. So, by immobilization of ionic liquids on the surface of copper ferrite nanoparticles, the advantage such as high surface area and reusability could be achieved.

To the best of our knowledge, there is no report of magnetic ionic liquid-supported $\mathrm{H} 5 \mathrm{BW} 12 \mathrm{O} 40$ as a heterogeneous catalyst. In this paper, we present the preparation and characterization of magnetically recoverable 1-(copperferritesiloxypropyl)-3-methylimidazolium heteropolytungstate ionic liquid nanoparticles and evaluate its catalytic activity in the synthesis of $1 \mathrm{H}$-pyrazolo[1,2b]phthalazine-5,10-diones under solvent-free conditions (Scheme 1).

\section{Experimental}

\section{Material and instrumentation}

All reagents and starting materials were purchased from Merck and Sigma-Aldrich chemical companies and were used as received. Fourier transform infrared spectra were recorded on 8700 Shimadzu Fourier transform spectrophotometer using $\mathrm{KBr}$ pellets in the region of $400-4000 \mathrm{~cm}^{-1}$. The powder X-ray diffraction (XRD) pattern was recorded with Philips PW1730 X-ray diffractometer. Field emission scanning electron microscopy (FESEM) photographs were obtained using Hitachi S-4160 microscope. Magnetic susceptibility measurements of nanoparticles were taken using a vibrating sample magnetometer (VSM) (BHV-55, Riken, Japan) at room temperature. Elemental analysis was performed by inductivity coupled plasma on Varian, Australia, ICP-OES, model Vista Pro spectrometry. Melting points were measured using the capillary tube method with a Barnstead electrothermal type 9200 melting points apparatus. The progress of the catalytic reaction was monitored by thin layer chromatography.

\section{Catalyst preparation}

\section{Synthesis of $\mathrm{H}_{5} \mathrm{~B} W_{12} \mathrm{O}_{40}$ heteropoly acid}

First, the $\mathrm{K}_{5}\left[\mathrm{BW}_{12} \mathrm{O}_{40}\right]$ salt was synthesized according to reported method by Rocchiccioli-deltcheff et al. [15]. Then, the prepared heteropoly anion, $\mathrm{K}_{5}\left[\mathrm{BW}_{12} \mathrm{O}_{40}\right]$, was converted into the corresponding acid by passing it through a column of Dowex-50W-X8 ion exchange resin. A sample of $\mathrm{K}_{5}\left[\mathrm{BW}_{12} \mathrm{O}_{40}\right](3 \mathrm{~g})$ was dissolved in $60 \mathrm{ml}$ water; then, the solution was passed through the resin column in the $\mathrm{H}^{+}$ form. This process was repeated for two times. Slow evaporation of the final solution gives the pure $\mathrm{H}_{5} \mathrm{BW}_{12} \mathrm{O}_{40}$ heteropoly acid.

\section{Synthesis of copper ferrite nanoparticles $\left(\mathrm{CuFe}_{2} \mathrm{O}_{4}\right)$}

$\mathrm{CuFe}_{2} \mathrm{O}_{4}$ (magnetic) nanoparticles were prepared by thermal decomposition of $\mathrm{Cu}\left(\mathrm{NO}_{3}\right)_{2} \cdot 3 \mathrm{H}_{2} \mathrm{O}$ and $\mathrm{Fe}\left(\mathrm{NO}_{3}\right)_{3-}$ $9 \mathrm{H}_{2} \mathrm{O}$ with molar ratio of $1: 2 \mathrm{in}$ basic solution, as reported by Dandia et al. [16].

\section{Preparation of ionic liquid-modified magnetic nanoparticles (ILMNPs)}

First of all, $\mathrm{CuFe}_{2} \mathrm{O}_{4}(1 \mathrm{~g})$ was dispersed in $100 \mathrm{ml}$ of toluene and ultrasonicated for $10 \mathrm{~min}$, and then, chloropropyl trimethoxysilane $(2 \mathrm{ml})$ was added dropwise to the mixture and refluxed under dry nitrogen atmosphere for $24 \mathrm{~h}$. The resulted chloropropyl-modified magnetic nanoparticles (ClpMNPs) were magnetically separated and washed with ethanol and dried at $70{ }^{\circ} \mathrm{C}$. Secondly, the obtained ClpMNPs $(2 \mathrm{~g})$ was suspended in $100 \mathrm{ml}$ of

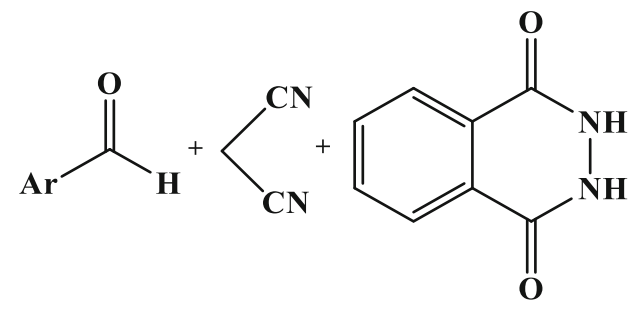

Scheme 1 Synthesis of 1H-pyrazolo[1,2-b]phthalazine-5,10-diones<smiles>N#CC1=C(N)n2c(=O)c3ccccc3c(=O)n2C1[123I]</smiles>

4a-s 


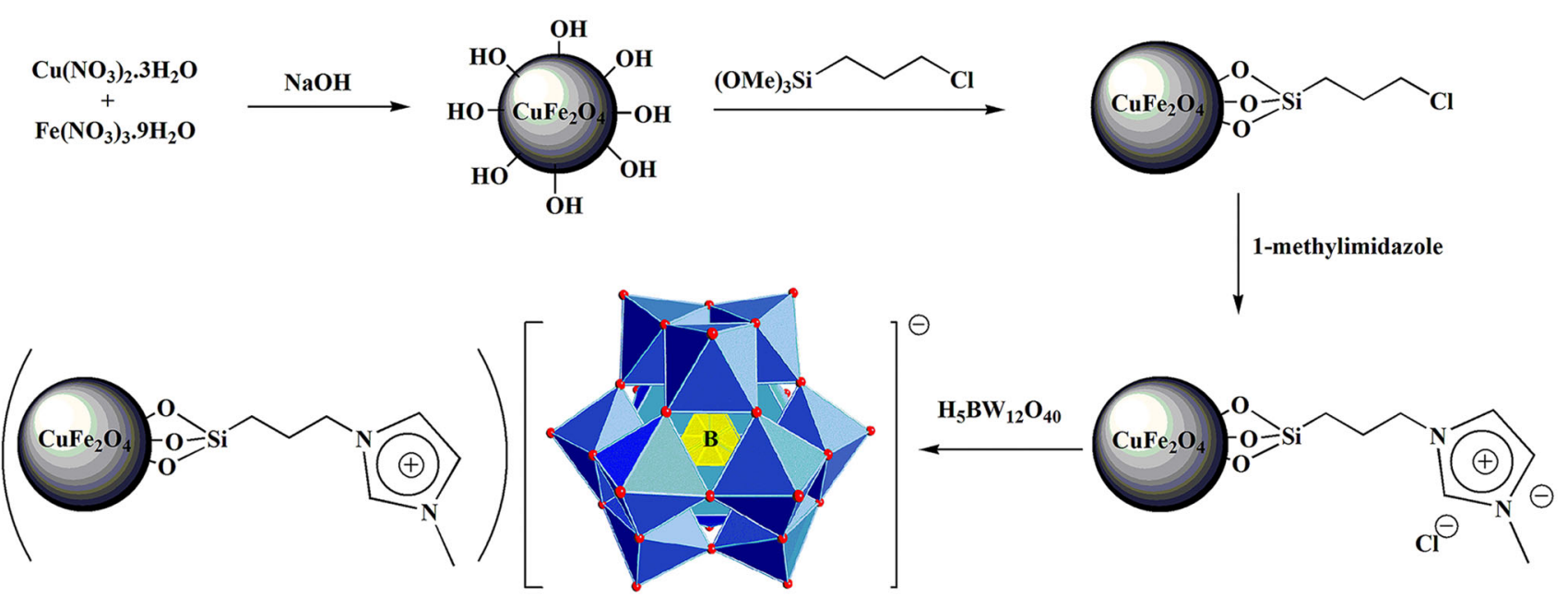

Scheme 2 Procedure for the preparation of $\mathrm{BW}_{12}$-ILMNPs

Fig. 1 FT-IR spectra of a $\mathrm{CuFe}_{2} \mathrm{O}_{4}$, b ClpMNPs, c ILMNPs and $\mathbf{d} \mathrm{BW}_{12^{-}}$ ILMNPs

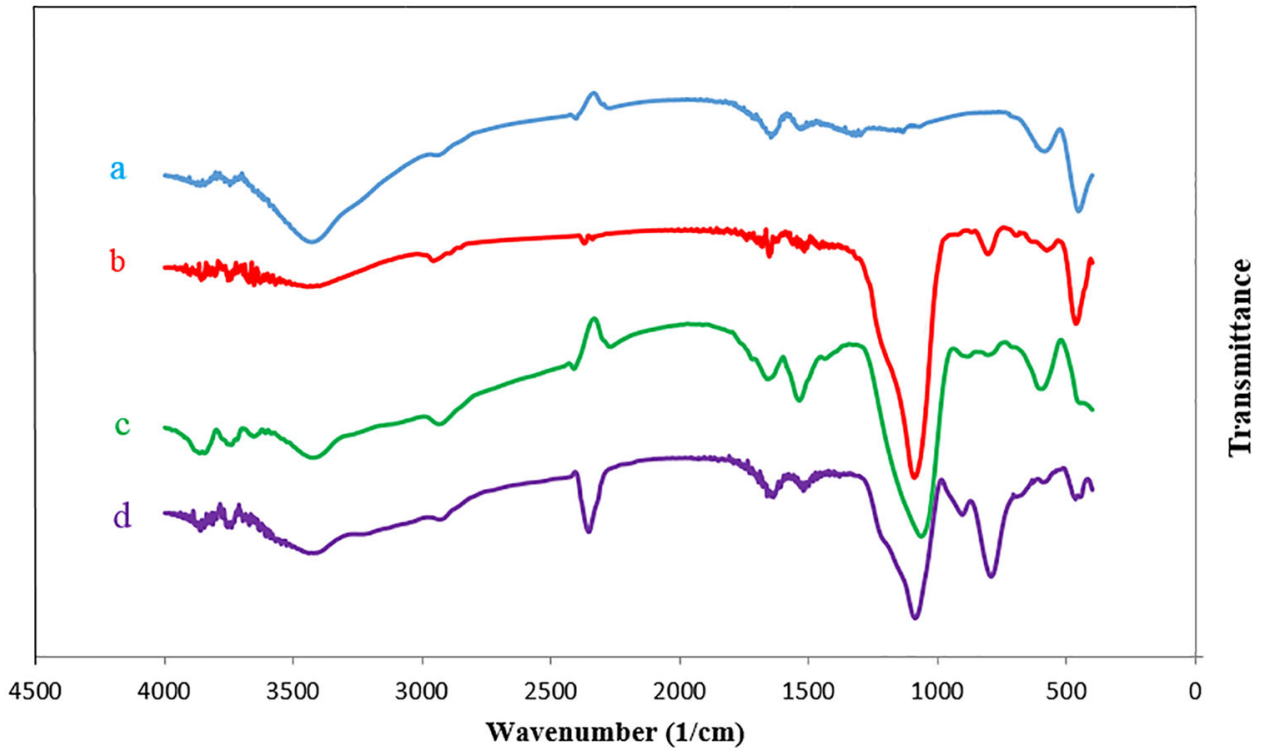

Table 1 Result of chemical analysis of prepared nanomaterial

\begin{tabular}{lll}
\hline Material & $N(\mathrm{mmol} / \mathrm{g})$ & $W(\mathrm{mmol} / \mathrm{g})$ \\
\hline ILMNPs & 1.58 & - \\
BW $_{12}$-ILMNPs $(\mathrm{g})$ & 1.41 & 1.74 \\
\hline
\end{tabular}

acetonitrile, and then, 1-methylimidazole (4 mmol) and triethylamine $(0.5 \mathrm{ml})$ were added to the mixture and refluxed for $24 \mathrm{~h}$. The obtained ionic liquid-modified magnetic nanoparticles (ILMNPs) were collected by magnetic field and washed abundantly with ethanol and dried at $70{ }^{\circ} \mathrm{C}$.

Finally, ILMNPs $(1 \mathrm{~g})$ were suspended in $70 \mathrm{ml}$ deionized water. Then, a solution of $\mathrm{H}_{5} \mathrm{BW}_{12} \mathrm{O}_{40}(2 \mathrm{mmol})$ in $30 \mathrm{ml}$ deionized water was added to the above mixture and stirred for $12 \mathrm{~h}$. The resulted solid was collected by magnetic field and washed with ethanol and dried at $60{ }^{\circ} \mathrm{C}$.

\section{Catalytic reaction}

General procedure for the preparation of $1 \mathrm{H}$-pyrazolo[1,2b]phthalazine-5,10-diones

$0.05 \mathrm{~g}$ of $\mathrm{BW}_{12}$-ILMNPs was added to a mixture of aromatic aldehyde $(1.0 \mathrm{mmol})$, malononitrile $(1.0 \mathrm{mmol})$ and phthalhydrazide $(1.0 \mathrm{mmol})$. Then, the mixture was stirred at $80{ }^{\circ} \mathrm{C}$ in an oil bath under solvent-free condition for the appropriate time as indicated in Table 4. After the end of the reaction, which was monitored by TLC, the mass was cooled to $25^{\circ} \mathrm{C}$ and then was dissolved in boiling ethanol, 


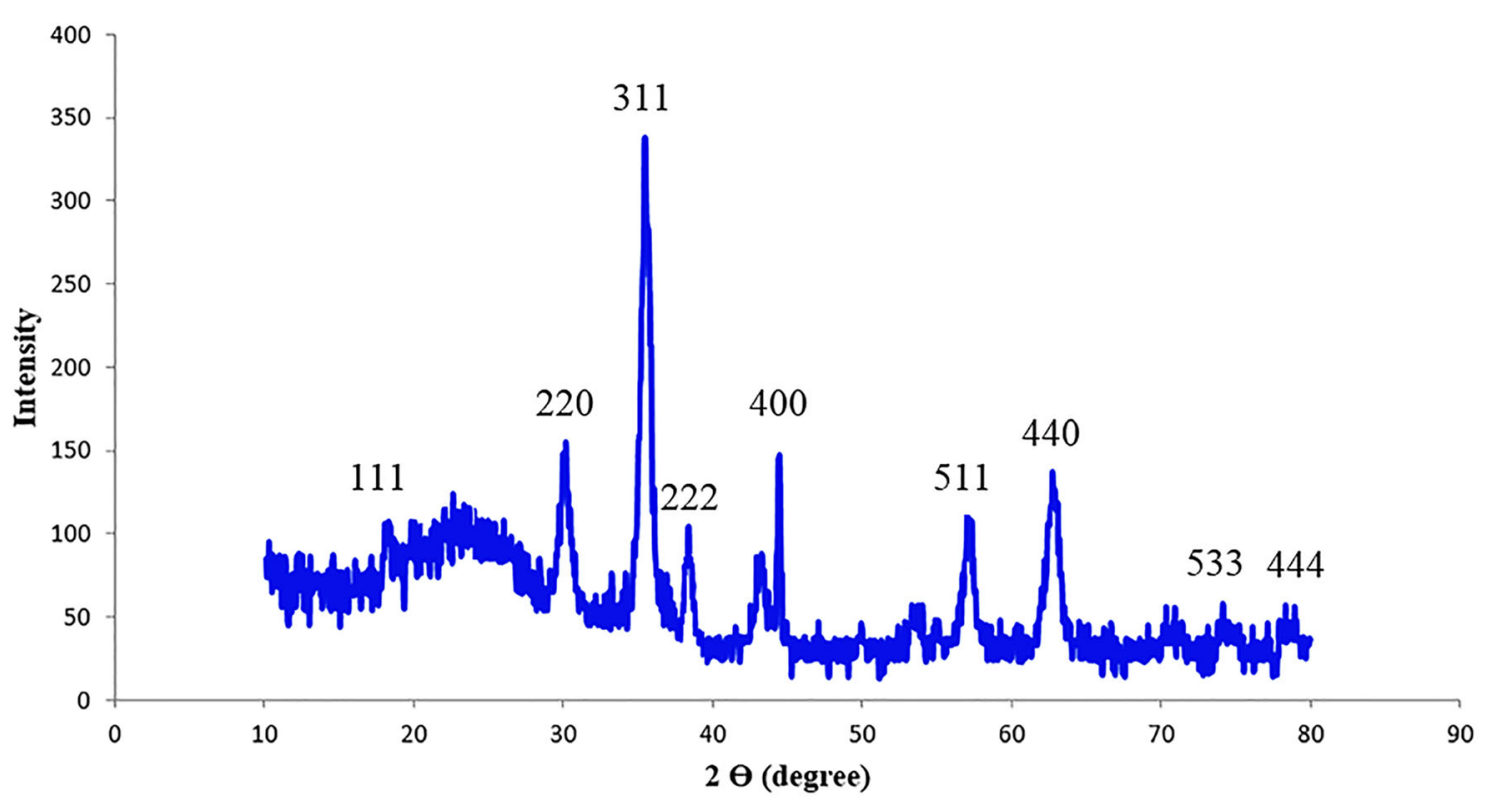

Fig. 2 XRD spectrum of $\mathrm{BW}_{12}$-ILMNPs

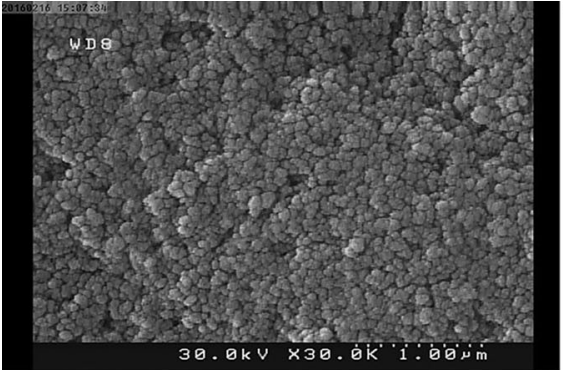

(a)

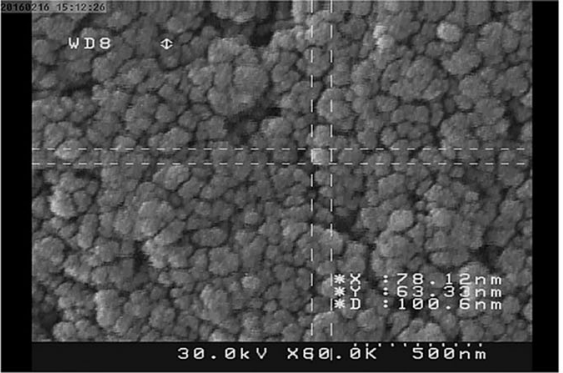

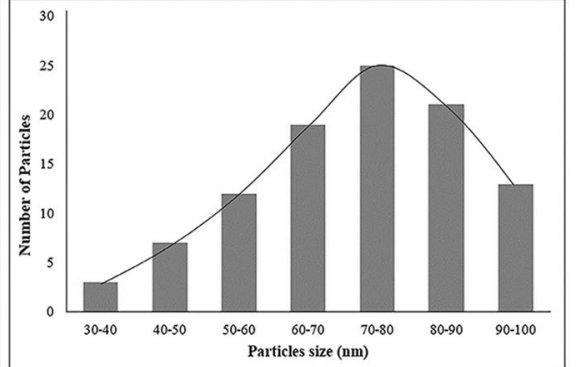

(b)

Fig. 3 FESEM images (a), size distribution (histogram) curve (b) of prepared nanomaterial

and catalyst was separated by an external magnet. Consequently, the liquor was poured into ice. After the crude product was separated by simple filtration, the pure $1 \mathrm{H}$ pyrazolo[1,2-b]phthalazine-5,10-dione derivative was obtained through recrystallization from ethanol. The product purity was determined by comparison with their physical data (melting point and FT-IR spectrum) with known compounds in articles.

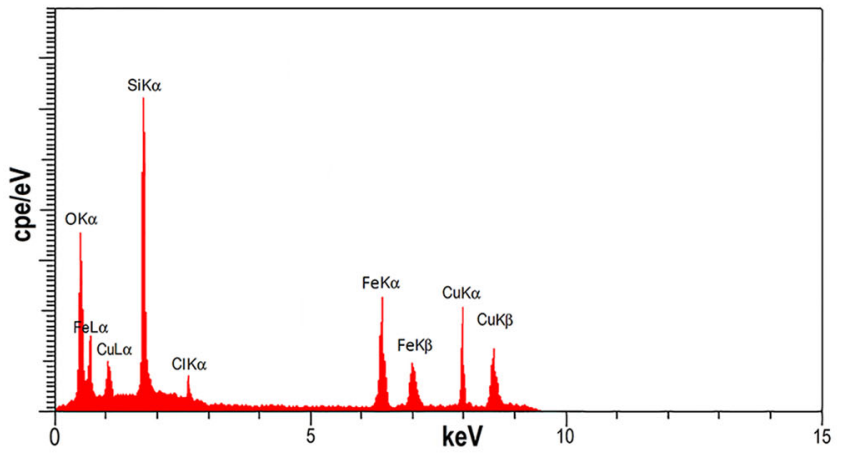

(a)

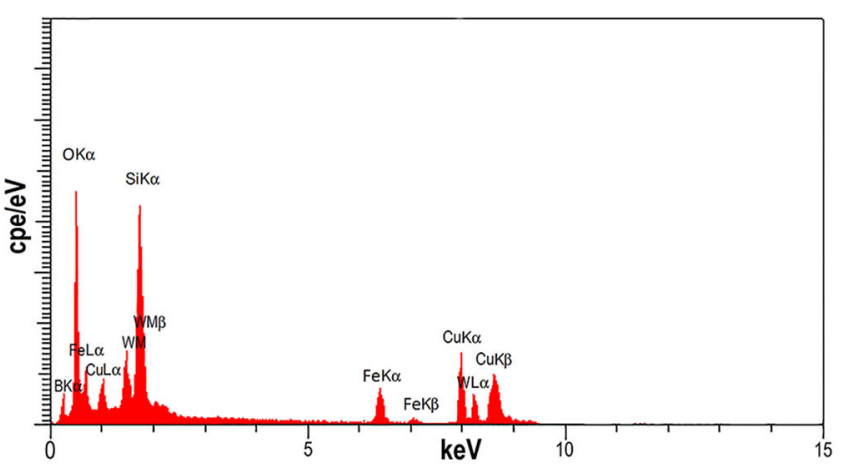

(b)

Fig. 4 EDX analysis of ILMNPs (a) and BW 12 -ILMNPs (b) 


\section{Result and discussion}

\section{Catalyst preparation and characterization}

Scheme 2 illustrates the procedure used for the preparation of magnetic nanocatalyst. In the first step, $\mathrm{CuFe}_{2} \mathrm{O}_{4}$ nanoparticles have been prepared by the thermal decomposition of $\mathrm{Fe}^{3+}$ and $\mathrm{Cu}^{2+}$ in basic solution [16]. Then, treatment of $\mathrm{CuFe}_{2} \mathrm{O}_{4}$ with (3-chloropropyl)trimethoxysilane affords ClpMNPs and substitution of chloro groups from ClpMNPS with 1-methyl imidazole yielded ILMNPs. At the last step, addition of $\mathrm{H}_{5} \mathrm{BW}_{12} \mathrm{O}_{40}$ heteropoly acid to ILMNPs affords BW12-ClpMNPs. Imidazolium cations bounds electrostatically to the produced heteropoly anion. It has been shown that heteropoly anion salt of organic cations are generally insoluble in water [17]. Therefore, the excess of HPA can be simply removed by washing the resulting material with water.

\section{FT-IR spectroscopy}

FT-IR spectra of the prepared $\mathrm{CuFe}_{2} \mathrm{O}_{4}$ (a), ClpMNPs (b), ILMNPs (c) and BW 12 -ILMNPs (d) are shown in Fig. 1. The appeared peaks around 450 and $580 \mathrm{~cm}^{-1}$ which were attributed to the $\mathrm{Fe}_{2} \mathrm{O}_{3}$ and $\mathrm{CuO}$ vibrational modes demonstrate the formation of $\mathrm{CuFe}_{2} \mathrm{O}_{4}$ magnetic core in the prepared nanomaterials [18]. The broad peak at about $1080 \mathrm{~cm}^{-1}$ assigns to $\mathrm{Si}-\mathrm{O}-\mathrm{Si}$ stretching vibrations which indicates survival of $\mathrm{SiO}_{2}$ layer around the $\mathrm{CuFe}_{2} \mathrm{O}_{4}$ nanoparticles [19]. The peak at $3400 \mathrm{~cm}^{-1}$ is attributed to the $\mathrm{O}-\mathrm{H}$ stretching. The stretching vibrations at about $2935 \mathrm{~cm}^{-1}$ in the spectrum of ClpMNPs confirm the anchored propyl groups. In the FT-IR spectrum of ILMNPs, two new peaks at 1656 and $1533 \mathrm{~cm}^{-1}$ are belonging to stretching vibration of aromatic ring. Keggintype HPAs have four characteristic peaks in wavenumber

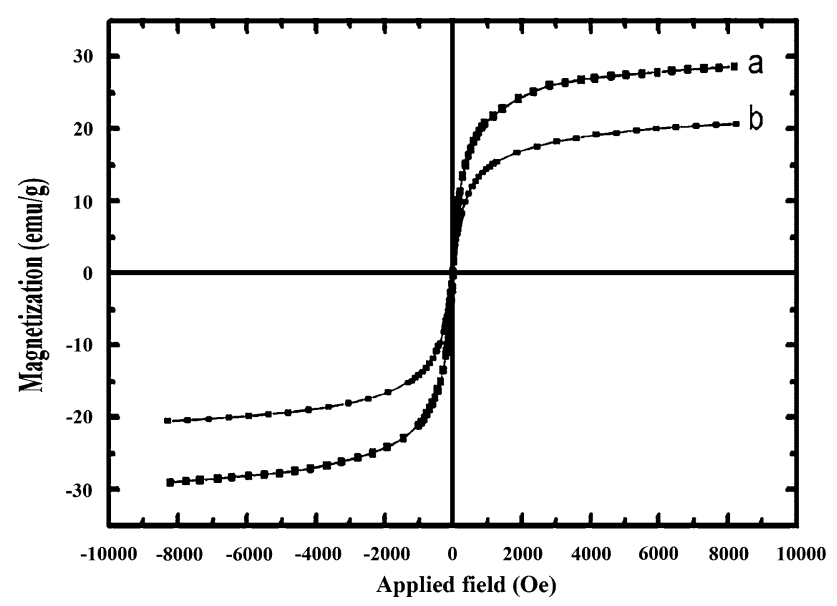

Fig. 5 Magnetization curves of (a) $\mathrm{CuFe}_{2} \mathrm{O}_{4}$ and (b) $\mathrm{BW}_{12}$-ILMNPs region $750-1100 \mathrm{~cm}^{-1}$, which in the $\mathrm{BW}_{12}$-ILMNPS spectra (Fig. 1d) become manifest at 900 and $792 \mathrm{~cm}^{-1}$ (corner and edge sharing $\mathrm{W}-\mathrm{O}-\mathrm{W}$ vibrations) [20]. The attributed peak to the $\mathrm{W}=\mathrm{O}$ stretching has interference from $\mathrm{Si}-\mathrm{O}-\mathrm{Si}$ stretching absorbance. The increase in the $\mathrm{W}-\mathrm{O}-\mathrm{W}$ stretching vibrations frequencies of prepared nanomaterial in comparison with neat HPAs is due to strong interaction between heteropoly anion and organic cation [21]. Accordingly, the FT-IR spectroscopy confirms the surface modification of magnetic nanoparticles and preparation of $\mathrm{BW}_{12}$-ILMNPs.

\section{Chemical analysis}

Table 1 shows the chemical analysis of the prepared nanomaterial. It demonstrates the loading of heteropoly acid, where its loading amount is equal to the $\mathrm{W}$ content of the prepared nanomaterial. Accordingly, the loading amount of heteropoly acid is $0.145 \mathrm{mmol} / \mathrm{g}$. On the other hand, the loading amount of nitrogen in $\mathrm{BW}_{12}$-ILMNPs is $1.41 \mathrm{mmol} / \mathrm{g}$. Therefore, the amount of supported 1-methylimidazole is $0.705 \mathrm{mmol} / \mathrm{g}$ and the ratio of imidazolium group to heteropoly acid is approximately 1:5. Furthermore, acid-base titration was performed using a Metrohm 809 Titrando for evaluating the acidity of catalyst. The titration of acidic groups was accomplished using the catalyst slurry containing $50 \mathrm{mg}$ of catalyst in deionized water, and a solution containing $0.01 \mathrm{M} \mathrm{NaOH}$ was used as titrant. The amount of titrant consumed to reach $\mathrm{pH}$ 7.5 revealed that the amount of acidic groups is about $0.697 \mathrm{mmol} / \mathrm{g}$.

\section{X-ray diffraction (XRD) study}

Figure 2 depicts the X-ray diffraction of $\mathrm{BW}_{12}$-ILMNPs. The marked diffraction peaks can be assigned to the planes of cubic spinel structured $\mathrm{CuFe}_{2} \mathrm{O}_{4}$ (JCPDS No. 250283). The broad peak appeared at $2 \theta$ of ca. $23^{\circ}$ indicates that the silica layer around the $\mathrm{CuFe}_{2} \mathrm{O}_{4}$ nanoparticles is in amorphous form. The prepared $\mathrm{BW}_{12}$-ILMNPs displays common diffraction peaks of $\mathrm{CuFe}_{2} \mathrm{O}_{4}$ nanoparticles and silica layer around them. Generally, it indicates that heteropoly anion species are well dispersed on the surface of ILMNPs.

\section{FESEM study}

The surface morphology and particle size of $\mathrm{BW}_{12^{-}}$ ILMNPs were studied by FESEM as shown in Fig. 3a. According to the FESEM images, it was confirmed that prepared nanoparticles are approximately spherical. Also, the aggregation gives rise to the increasing size of observed nanoparticles. The presented FESEM images of $\mathrm{BW}_{12^{-}}$ ILMNPs display that the average size of these 


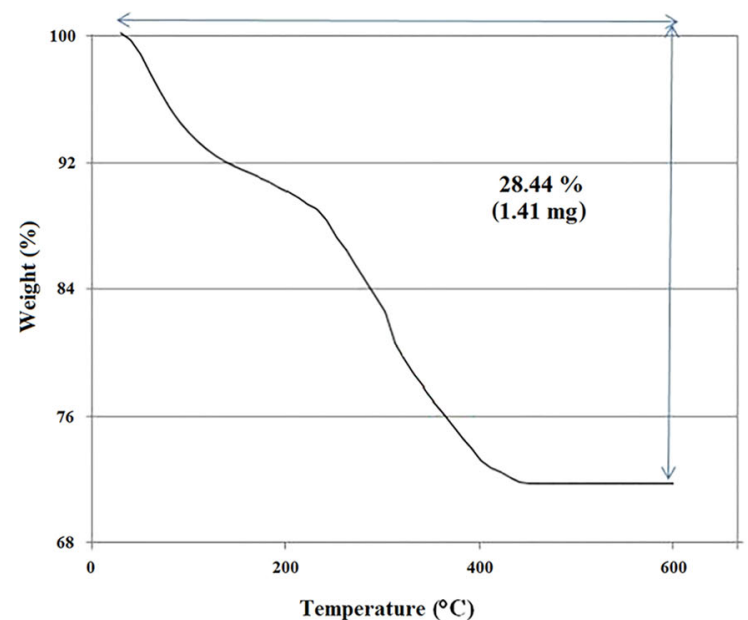

(a)

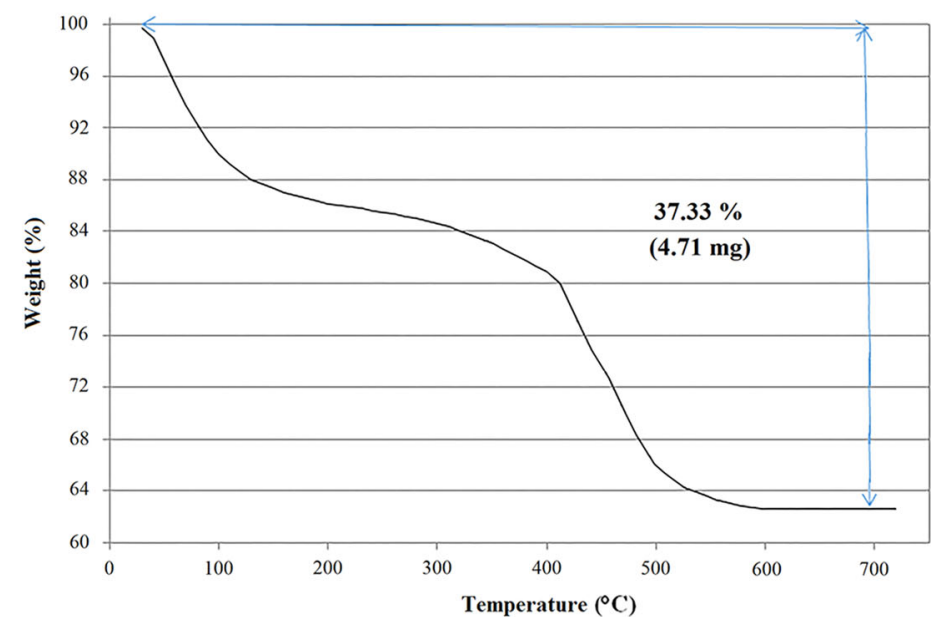

(b)

Fig. 6 TGA analysis of ILMNPs (a) and BW 12 -ILMNPs (b)

Table 2 Effect of catalyst amount on the synthesis of 1H-pyrazolo[1,2-b]phthalazine-5,10-dione

\begin{tabular}{lllc}
\hline Entry & BW $_{12}$-ILMNPs $(\mathrm{g})$ & Time $(\mathrm{min})$ & Yield $(\%)$ \\
\hline 1 & 0 & 180 & 0 \\
2 & 0.01 & 20 & 18 \\
3 & 0.03 & 10 & 62 \\
4 & 0.05 & 10 & 90 \\
5 & 0.1 & 10 & 84 \\
\hline
\end{tabular}

Reaction conditions: benzaldehyde, malononitrile and phthalhydrazide $(1: 1: 1 \mathrm{mmol})$ were mixed in $80{ }^{\circ} \mathrm{C}$ under solvent-free condition

Table 3 Effect of reaction temperature on the synthesis of $1 \mathrm{H}$ pyrazolo[1,2-b]phthalazine-5,10-dione

\begin{tabular}{lll}
\hline Entry & Temperature $\left({ }^{\circ} \mathrm{C}\right)$ & Yield $(\%)$ \\
\hline 1 & 25 & 34 \\
2 & 40 & 47 \\
3 & 60 & 69 \\
4 & 80 & 90 \\
5 & 100 & 81 \\
\hline
\end{tabular}

Reaction conditions: benzaldehyde, malononitrile and phthalhydrazide $(1: 1: 1 \mathrm{mmol})$ were mixed in the presence of $0.05 \mathrm{~g}$ of $\mathrm{BW}_{12^{-}}$ ILMNPs for $10 \mathrm{~min}$ under solvent-free conditions

nanoparticles is in the range of $70-80 \mathrm{~nm}$. Furthermore, Fig. $3 \mathrm{~b}$ shows the size distribution of nanoparticles which is determined by measuring diameters of one hundred nanoparticles randomly selected on the FESEM images. As can be seen, the distribution is symmetric around $70-80 \mathrm{~nm}$ and the most of the particles have the size between 60 and $90 \mathrm{~nm}$.
Table 4 Effect of reaction time on the synthesis of $1 \mathrm{H}$-pyrazolo[1,2-b]phthalazine-5,10dione

The chemical identity of ILMNPs and $\mathrm{BW}_{12}$-ILMNPs was confirmed by EDX analysis (Fig. 4). The EDX analysis of ILMNPs (Fig. 4a) showed the presence of $\mathrm{Fe}, \mathrm{Cu}$, $\mathrm{O}, \mathrm{Si}$ and $\mathrm{Cl}$, whereas the EDX analysis of $\mathrm{BW}_{12}$-ILMNPs (Fig. 4b) indicated the coexistence of $\mathrm{Fe}, \mathrm{Cu}, \mathrm{O}, \mathrm{Si}, \mathrm{B}$ and $\mathrm{W}$ in the nanoparticles and proved that the heteropoly acid replaced with $\mathrm{Cl}$ and $\mathrm{BW}_{12}$-ILMNPs has formed.

\section{The study of magnetic property}

Magnetic measurement of $\mathrm{CuFe}_{2} \mathrm{O}_{4}$ and $\mathrm{BW}_{12}$-ILMNPs is shown in Fig. 5. No remanence effect was observed in the magnetization diagram of nanomaterials, which indicating the superparamagnetic property. Furthermore, magnetization saturation values for $\mathrm{CuFe}_{2} \mathrm{O}_{4}$ and $\mathrm{BW}_{12}$-ILMNPs are 48 and $25 \mathrm{emu} / \mathrm{g}$, respectively. The mass saturation magnetization reduction would be attributed to the presence of the silica shell and functionalized groups around the $\mathrm{CuFe}_{2} \mathrm{O}_{4}$ core. The importance of superparamagnetic property of resulted $\mathrm{BW}_{12}$-ILMNPs is due to its 
Table 5 Comparison of the catalytic activity of $\mathrm{BW}_{12}$ ILMNPs with some reported catalysts used for the synthesis of $1 \mathrm{H}$-pyrazolo[1,2b]phthalazine-5,10-diones
Table 6 Synthesis of $1 \mathrm{H}-$ pyrazolo[1,2-b]phthalazine5,10-dione derivatives

\begin{tabular}{llllll}
\hline Entry & Catalyst & Time & Condition & Yield (\%) & References \\
\hline 1 & $\mathrm{Et}_{3} \mathrm{~N}$ & $60 \mathrm{~min}$ & Ultrasound, $50{ }^{\circ} \mathrm{C}$ & 91 & {$[4]$} \\
2 & Supported caesium carbonate & $15 \mathrm{~min}$ & Solvent-free, $110{ }^{\circ} \mathrm{C}$ & 93 & {$[5]$} \\
3 & $\mathrm{CuI} \mathrm{NPs}$ & $25 \mathrm{~min}$ & Solvent-free, $80{ }^{\circ} \mathrm{C}$ & 92 & {$[6]$} \\
4 & $\mathrm{Al}-\mathrm{KIT}-6$ & $4 \mathrm{~h}$ & Ethanol, $60{ }^{\circ} \mathrm{C}$ & 93 & {$[7]$} \\
5 & $\mathrm{NiCl}_{2} \cdot 6 \mathrm{H}_{2} \mathrm{O}$ & $3 \mathrm{~h}$ & Ethanol, reflux & 90 & {$[8]$} \\
6 & $\mathrm{InCl}_{3}$ & $25 \mathrm{~min}$ & Solvent-free, $80{ }^{\circ} \mathrm{C}$ & 94 & {$[9]$} \\
7 & $\mathrm{SBA}-$ supported sulfonic acid & $20 \mathrm{~min}$ & Solvent-free, $80{ }^{\circ} \mathrm{C}$ & 90 & {$[10]$} \\
8 & $p-\mathrm{Toluenesulfonic} \mathrm{acid}_{3}$ & $3 \mathrm{~h}$ & {$\left[\right.$ bmim]Br, $100{ }^{\circ} \mathrm{C}$} & 94 & {$[11]$} \\
9 & $\mathrm{CuFe}_{2} \mathrm{O}_{4}$ & $60(\mathrm{~min})$ & Solvent-free, $80{ }^{\circ} \mathrm{C}$ & 35 & This work \\
10 & $\mathrm{ILMNPs}_{11}$ & $60(\mathrm{~min})$ & Solvent-free, $80{ }^{\circ} \mathrm{C}$ & - & This work \\
& $\mathrm{BW}_{12}$-ILMNPs & 10 & Solvent-free, $80{ }^{\circ} \mathrm{C}$ & 90 & This work \\
\hline
\end{tabular}

\begin{tabular}{|c|c|c|c|c|c|}
\hline \multirow[t]{2}{*}{ Entry } & \multirow[t]{2}{*}{ Aldehyde } & \multirow[t]{2}{*}{ Product } & \multirow[t]{2}{*}{ Yield (\%) } & \multicolumn{2}{|l|}{ M.P. } \\
\hline & & & & Observed & Reported [references] \\
\hline 1 & $\mathrm{C}_{6} \mathrm{H}_{5}-\mathrm{CHO}$ & $4 a$ & 90 & $276-278$ & $275-276[12]$ \\
\hline 2 & $2-\mathrm{ClC}_{6} \mathrm{H}_{4}-\mathrm{CHO}$ & $4 b$ & 91 & $256-257$ & $257-259$ [12] \\
\hline 3 & $3-\mathrm{ClC}_{6} \mathrm{H}_{4}-\mathrm{CHO}$ & $4 \mathrm{c}$ & 93 & $265-267$ & $266-268[12]$ \\
\hline 4 & $4-\mathrm{ClC}_{6} \mathrm{H}_{4}-\mathrm{CHO}$ & $4 d$ & 91 & $273-275$ & $272[12]$ \\
\hline 5 & $2,4-(\mathrm{Cl})_{2} \mathrm{C}_{6} \mathrm{H}_{3}-\mathrm{CHO}$ & $4 \mathrm{e}$ & 93 & $244-246$ & $248-250[12]$ \\
\hline 6 & 2,6- $(\mathrm{Cl})_{2} \mathrm{C}_{6} \mathrm{H}_{3}-\mathrm{CHO}$ & $4 \mathrm{f}$ & 88 & $260-262$ & $259-261[12]$ \\
\hline 7 & $3-\mathrm{BrC}_{6} \mathrm{H}_{4}-\mathrm{CHO}$ & $4 \mathrm{~g}$ & 92 & $266-268$ & $271[12]$ \\
\hline 8 & $4-\mathrm{BrC}_{6} \mathrm{H}_{4}-\mathrm{CHO}$ & $4 \mathrm{~h}$ & 90 & $265-267$ & $263-264[12]$ \\
\hline 9 & $2-(\mathrm{OMe}) \mathrm{C}_{6} \mathrm{H}_{4}-\mathrm{CHO}$ & $4 \mathrm{i}$ & 80 & $255-257$ & $259-260[12]$ \\
\hline 10 & $3-(\mathrm{OMe}) \mathrm{C}_{6} \mathrm{H}_{4}-\mathrm{CHO}$ & $4 j$ & 88 & $244-246$ & $248-251[12]$ \\
\hline 11 & $4-(\mathrm{OMe}) \mathrm{C}_{6} \mathrm{H}_{4}-\mathrm{CHO}$ & $4 \mathrm{k}$ & 84 & $198-200$ & 192-194 [5] \\
\hline 12 & $3,4-(\mathrm{OMe})_{2} \mathrm{C}_{6} \mathrm{H}_{3}-\mathrm{CHO}$ & 41 & 85 & $154-156$ & $150-152[5]$ \\
\hline 13 & $4-\mathrm{CH}_{3} \mathrm{C}_{6} \mathrm{H}_{4}-\mathrm{CHO}$ & $4 \mathrm{~m}$ & 72 & $252-254$ & $253-256[5]$ \\
\hline 14 & $2-\mathrm{NO}_{2} \mathrm{C}_{6} \mathrm{H}_{4}-\mathrm{CHO}$ & $4 n$ & 94 & $266-268$ & $265-267[12]$ \\
\hline 15 & $3-\mathrm{NO}_{2} \mathrm{C}_{6} \mathrm{H}_{4}-\mathrm{CHO}$ & 40 & 97 & $264-266$ & $269-271[12]$ \\
\hline 16 & $4-\mathrm{NO}_{2} \mathrm{C}_{6} \mathrm{H}_{4}-\mathrm{CHO}$ & $4 p$ & 96 & $230-232$ & $228-229[12]$ \\
\hline 17 & $3-\mathrm{OHC}_{6} \mathrm{H}_{4}-\mathrm{CHO}$ & $4 \mathrm{q}$ & 65 & $269-271$ & $270-272[5]$ \\
\hline 18 & $4-\mathrm{CH}\left(\mathrm{CH}_{3}\right)_{2} \mathrm{C}_{6} \mathrm{H}_{4}-\mathrm{CHO}$ & $4 \mathrm{r}$ & 58 & $270-271$ & 264-266 [6] \\
\hline 19 & $4-\mathrm{N}\left(\mathrm{CH}_{3}\right)_{2} \mathrm{C}_{6} \mathrm{H}_{4}-\mathrm{CHO}$ & $4 \mathrm{~s}$ & 61 & $230-232$ & $230-232[5]$ \\
\hline
\end{tabular}

applications, which prevents aggregation and enables it to redisperse swiftly after removal of magnetic field.

\section{The study of thermal reliability}

Figure 6 shows TGA curves of the ILMNPs and $\mathrm{BW}_{12}$ ILMNPs heated under $\mathrm{N}_{2}$ atmosphere at $10{ }^{\circ} \mathrm{C} / \mathrm{min}$. As can be seen, the ILMNPs (Fig. 6a) degrade in two steps, whereas the $\mathrm{BW}_{12}$-ILMNPs (Fig. 6b) degrade in three steps. It demonstrates that the third step in Fig. 6b is due to decomposition of heteropoly acid. The ILMNPs and $\mathrm{BW}_{12-}$ ILMNPs start to lose weight at approximately $50{ }^{\circ} \mathrm{C}$ which could be due to loss of water. The observed slope around
200-400 ${ }^{\circ} \mathrm{C}$ leads to loss of weight that could be assigned to decomposition of anchored propyl and imidazolium group. Above $400{ }^{\circ} \mathrm{C}$, the supported heteropoly acid starts to decompose and the mass loss of it is about $18 \%$.

Studying catalytic activity of $B W_{12}$ ILMNPs in $1 H$ pyrazolo[1,2-b]phthalazine-5,10-diones synthesis

The best experimental route was procured via optimization of the catalysts amount (Table 2), reaction temperature (Table 3), reaction time (Table 4) and various catalysts (Table 5). 
Fig. 7 Reusability of $\mathrm{BW}_{12^{-}}$ ILMNPs

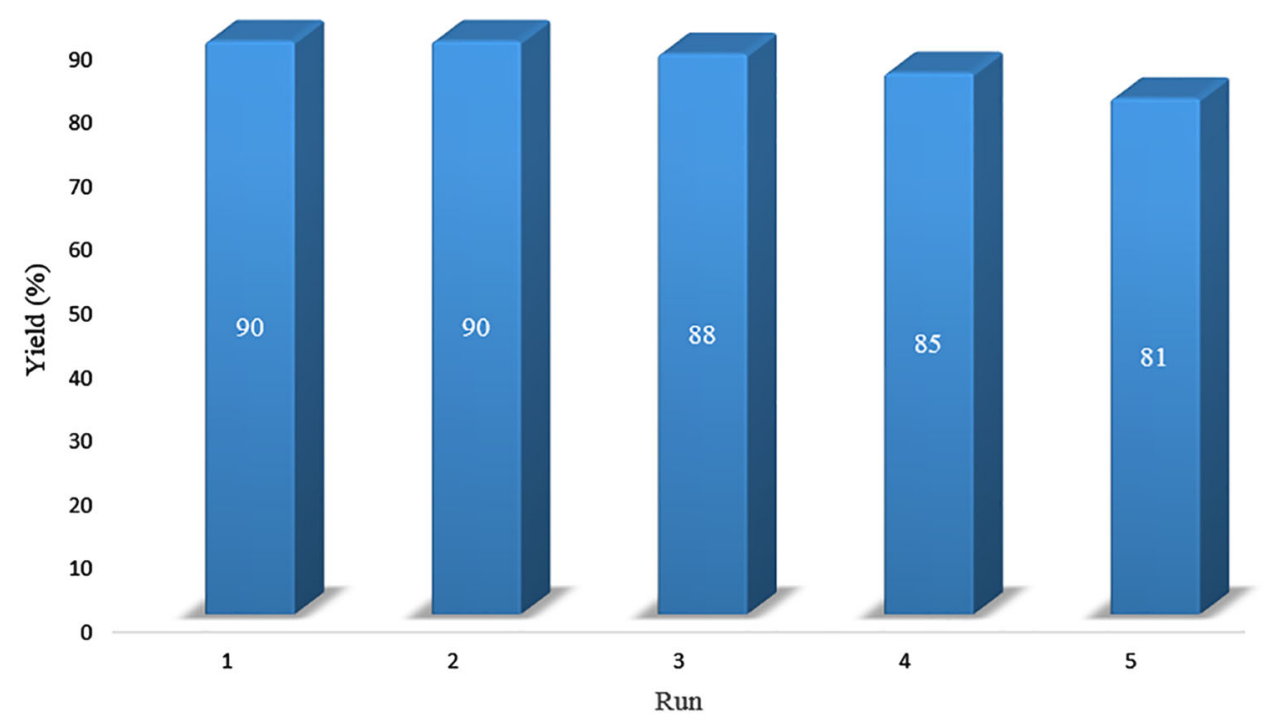

In order to peruse the appropriate amount of catalyst, $0-0.1 \mathrm{~g}$ of catalyst was added to a mixture of benzaldehyde (1 mmol), malononitrile $(1 \mathrm{mmol})$ and phthalhydrazide $(1 \mathrm{mmol})$ at $80^{\circ} \mathrm{C}$ under solvent-free conditions as the model reaction. Then, the mixture was stirred for appropriate time in an oil bath and the reaction was monitored by TLC.

After the completion of reaction, the crude product was purified as explained in "Experimental" section. The reaction did not occur in the absence of catalyst (Table 2 entry 1) which indicates that catalyst plays an important role in the reaction progress.

As is foretaste, yield \% was increasing with raising catalyst amount; therefore, $0.05 \mathrm{~g}$ of catalyst was chosen as the optimal quantity.

Then the effect of temperature was scrutinized under solvent-free conditions for $10 \mathrm{~min}$ in the presence of $0.05 \mathrm{~g}$ of nanocatalyst, and $80{ }^{\circ} \mathrm{C}$ was considered as optimal temperature (Table 3).

Eventually the effect of time was studied and revealed that the excellent condition was solvent-free at $80{ }^{\circ} \mathrm{C}$ in the presence of $0.05 \mathrm{~g}$ of catalyst for $10 \mathrm{~min}$ (Table 4).

The catalytic performance of prepared nanomaterial was compared with previously reported methods (Table 5). The superiority of the present catalyst in terms of reaction time and yield $\%$ is quite obvious. Furthermore, ease of catalyst separation, reaction conditions and economical aspects are other remarkable advantages of present methodology.

As given in Table 5 (entry 13), no reaction was done when ILMNPs was used as a catalyst. It demonstrates supported heteropoly acid is the active site for catalytic activity.

The obtained optimal conditions were exerted to a series of aromatic aldehydes containing either electron-donating or electron-withdrawing functional group in the ortho-, meta- and para-positions. The results are given in Table 6 . It appears that electron-withdrawing groups give rise to supreme yield of the products. Moreover, the applicability of reaction with aliphatic aldehydes under the optimized conditions was checked and observed that this reaction could not be done when the aliphatic aldehyde was used as a starting material.

Finally, the reusability of nanocatalyst was studied in model reaction under optimized conditions. After the separation of nanocatalyst by an external magnetic field at the end of the reaction, the catalyst was washed with ethanol and dried at $70{ }^{\circ} \mathrm{C}$ under vacuum for $2 \mathrm{~h}$. The recycled nanocatalyst was reused in another condensation reaction. Findings revealed that the nanocatalyst could be reused for at least five runs without significant loss of its catalytic activity as shown in Fig. 7.

\section{Conclusion}

In this study, a novel and efficient nanocatalyst was synthesized by the reaction of ionic liquid-modified magnetic nanoparticles with heteropoly anion. The obtained nanocatalyst displayed supreme catalytic efficiency in onepot three component condensation for the preparation of 1H-pyrazolo[1,2-b]phthalazine-5,10-diones. In comparison with previously reported methods, the present nanocatalyst provides an easy and convenient methodology for the preparation of $1 \mathrm{H}$-pyrazolo[1,2-b]phthalazine-5,10-diones. Some advantages of this procedure are operation simplicity, high yields, low reaction time, simple work-up, reusability and recyclability of magnetic nanocatalyst, avoidance of organic toxic solvents. 
Acknowledgements We are grateful to the University of Hakim Sabzevari Research council for the partial support of this research.

Open Access This article is distributed under the terms of the Creative Commons Attribution 4.0 International License (http://crea tivecommons.org/licenses/by/4.0/), which permits unrestricted use, distribution, and reproduction in any medium, provided you give appropriate credit to the original author(s) and the source, provide a link to the Creative Commons license, and indicate if changes were made.

\section{References}

1. Zhu, J., Bienaymé, H.: Multicomponent reactions. Wiley, Hoboken (2006)

2. Nefzi, A., Ostresh, J.M., Houghten, R.A.: The current status of heterocyclic combinatorial libraries. Chem. Rev. 97, 449-472 (1997)

3. Al'-Assar, F., Zelenin, K., Lesiovskaya, E., Bezhan, I., Chakchir, B.: Synthesis and pharmacological activity of 1-hydroxy-, 1-amino-, and 1-hydrazino-substituted 2, 3-dihydro-1H-pyrazolo [1, 2-a] pyridazine-5, 8-diones and 2, 3-dihydro-1H-pyrazolo [1, 2-b] phthalazine-5, 10-diones. Pharm. Chem. J. 36, 598-603 (2002)

4. Nabid, M.R., Rezaei, S.J.T., Ghahremanzadeh, R., Bazgir, A.: Ultrasound-assisted one-pot, three-component synthesis of $1 \mathrm{H}$ pyrazolo [1, 2-b] phthalazine-5, 10-diones. Ultrason. Sonochem. 17, 159-161 (2010)

5. Maleki, B., Chalaki, S.B.N., Ashrafi, S.S., Seresht, E.R., Moeinpour, F., Khojastehnezhad, A., Tayebee, R.: Caesium carbonate supported on hydroxyapatite-encapsulated $\mathrm{Ni0} \bullet 5 \mathrm{Zn} 0 \bullet 5 \mathrm{Fe}_{2} \mathrm{O}_{4}$ nanocrystallites as a novel magnetically basic catalyst for the one-pot synthesis of pyrazolo [1, 2-b] phthalazine5, 10-diones. Appl. Organomet. Chem. 5, 290-295 (2015)

6. Safaei-Ghomi, J., Shahbazi-Alavi, H., Ziarati, A., Teymuri, R., Saberi, M.R.: A highly flexible green synthesis of $1 \mathrm{H}-$ pyrazolo [1, 2-b] phthalazine-5, 10-dione derivatives with $\mathrm{CuI}$ nanoparticles as catalyst under solvent-free conditions. Chin. Chem. Lett. 25, 401-405 (2014)

7. Karthikeyan, G., Pandurangan, A.: Post synthesis alumination of KIT-6 materials with Ia3d symmetry and their catalytic efficiency towards multicomponent synthesis of $1 \mathrm{H}$-pyrazolo [1, 2-] phthalazine-5, 10-dione carbonitriles and carboxylates. J. Mol. Catal. A Chem. 361, 58-67 (2012)

8. Song, S.-H., Zhong, J., He, Y.-H., Guan, Z.: One-pot four-component synthesis of $1 \mathrm{H}$-pyrazolo [1, 2-b] phthalazine-5, 10-dione derivatives. Tetrahedron Lett. 53, 7075-7077 (2012)

9. Reddy, M.V., Jeong, Y.T.: InCl 3-catalyzed green synthesis of 1H-pyrazolo [1, 2-b] phthalazine-5, 10-diones under solvent-free conditions. Tetrahedron Lett. 54, 3546-3549 (2013)
10. Ziarani, G.M., Mohtasham, N.H., Badiei, A., Lashgari, N.: Efficient one-pot solvent-free synthesis of 1H-pyrazolo [1, 2-b] phthalazine-5, 10-diones catalyzed by sulfonic acid functionalized nanoporous silica (SBA-Pr-SO3H). J. Chin. Chem. Soc. 61, 990-994 (2014)

11. Ghahremanzadeh, R., Shakibaei, G.I., Bazgir, A.: An efficient one-pot synthesis of 1H-pyrazolo [1, 2-b] phthalazine-5, 10-dione derivatives. Synlett 2008, 1129-1132 (2008)

12. Shaterian, H.R., Mohammadnia, M.: Mild basic ionic liquids catalyzed new four-component synthesis of $1 \mathrm{H}$-pyrazolo [1, 2-b] phthalazine-5, 10-diones. J. Mol. Liq. 173, 55-61 (2012)

13. Zhao, D., Wu, M., Kou, Y., Min, E.: Ionic liquids: applications in catalysis. Catal. Today 74, 157-189 (2002)

14. Li, M., Pham, P.J., Pittman, C.U., Li, T.: SBA-15-supported ionic liquid compounds containing silver salts: novel mesoporous $\pi$ complexing sorbents for separating polyunsaturated fatty acid methyl esters. Microporous Mesoporous Mater. 117, 436-443 (2009)

15. Rocchiccioli-Deltcheff, C., Fournier, M., Franck, R., Thouvenot, R.: Vibrational investigations of polyoxometalates. 2. Evidence for anion-anion interactions in molybdenum (VI) and tungsten (VI) compounds related to the Keggin structure. Inorg. Chem. 22, 207-216 (1983)

16. Dandia, A., Jain, A.K., Sharma, S.: $\mathrm{CuFe}_{2} \mathrm{O}_{4}$ nanoparticles as a highly efficient and magnetically recoverable catalyst for the synthesis of medicinally privileged spiropyrimidine scaffolds. RSC Adv. 3, 2924-2934 (2013)

17. Kozhevnikov, I.: Catalysts for fine chemical synthesis, catalysis by polyoxometalates, vol. 2. Wiley, Hoboken (2002)

18. Sezgin, N., Sahin, M., Yalcin, A., Koseoglu, Y.: Synthesis, characterization and the heavy metal removal efficiency of $\mathrm{MFe}_{2} \mathrm{O}_{4}(\mathrm{M}=\mathrm{Ni}, \mathrm{Cu})$ Nanoparticles. Ekoloji 89, 89-96 (2013)

19. Alizadeh, A., Khodaei, M.M., Beygzadeh, M., Kordestani, D., Feyzi, M.: Biguanide-functionalized $\mathrm{Fe}_{3} \mathrm{O}_{4} / \mathrm{SiO}_{2}$ magnetic nanoparticles: an efficient heterogeneous organosuperbase catalyst for various organic transformations in aqueous media. Bull. Korean Chem. Soc. 33, 2546-2552 (2012)

20. Juan, J.C., Zhang, J., Yarmo, M.A.: 12-Tungstophosphoric acid supported on MCM-41 for esterification of fatty acid under solvent-free condition. J. Mol. Catal. A Chem. 267, 265-271 (2007)

21. Mosa, J., Larramona, G., Durán, A., Aparicio, M.: Synthesis and characterization of $\mathrm{P}_{2} \mathrm{O}_{5}-\mathrm{ZrO}_{2}-\mathrm{SiO}_{2}$ membranes doped with tungstophosphoric acid (PWA) for applications in PEMFC. J. Membr. Sci. 307, 21-27 (2008)

\section{Publisher's Note}

Springer Nature remains neutral with regard to jurisdictional claims in published maps and institutional affiliations. 